\title{
Educação do campo no Estado de São Paulo: análise do nível de ruralidade das escolas no desempenho escolar
}

Cláudia Souza Passador

Universidade de São Paulo (USP)

José Eduardo Ferreira Lopes

Universidade Federal de Uberlândia (UFU)

\begin{abstract}
Educação do campo no Estado de São Paulo: análise do nível de ruralidade das escolas no desempenho escolar
\end{abstract}

Este trabalho tem como objetivo central analisar a influência da localização da escola e da origem dos alunos (rural e urbano) na taxa de evasão, na taxa de aprovação/reprovação, no desempenho obtido no Ideb e na Prova Brasil. Para tanto, foram considerados os alunos do 5 o ano (quarta série) do ensino fundamental das redes municipais e estaduais do Estado de São Paulo. A tipologia do IBGE para classificação das escolas em rurais e urbanas e o local de moradia dos alunos foram utilizados como forma de caracterizar o nível de ruralidade das escolas. $\mathrm{O}$ trabalho organiza um diagnóstico das políticas em andamento; aponta algumas diretrizes para o aperfeiçoamento das futuras intervenções na área específica de atuação governamental; e mostra que, em várias situações, o desempenho das escolas "rurais", considerando os itens analisados, é inferior ao desempenho das escolas urbanas.

Palavras-chave: política educacional, educação, ensino público, indicador de desempenho, zona rural

Educación del campo en el Estado de Sao Paulo: análisis del nivel de ruralismo de las escuelas en el desempeño escolar

Este estudio tiene como objetivo analizar la influencia de la localización de la escuela y el origen de los estudiantes (rural y urbana) en relación con la tasa de deserción escolar, la tasa de aprobado/reprobado en el rendimiento obtenido en el Ideb y la Prova Brasil,

Artigo recebido em: outubro de 2013. Versão final em: fevereiro de 2014. 
para los estudiantes del quinto año (cuarto grado) de la escuela primaria municipal y estadual perteneciente al Estado de São Paulo, teniendo en cuenta la tipología de la clasificación del IBGE de las escuelas en las zonas rurales y urbanas y el lugar de residencia de los estudiantes como una forma de caracterizar el nivel de las escuelas rurales. El trabajo organiza un diagnóstico de las políticas en curso, sugiere algunas pautas para mejorar las intervenciones futuras en esta área de acción del gobierno y muestra que, en muchos casos, el desempeño de las escuelas "rurales" teniendo en cuenta los elementos analizados, es menor que el rendimiento de las escuelas urbanas.

Palabras clave: política educativa, educación, escuela pública, indicador de desempeño, zona rural

Education in rural areas of the state of São Paulo/Brazil: analyzing the effects of rurality levels on school performance

This paper aims to analyze the influence of the school location and origin of students (rural and urban) in the dropout rate, the rate of pass/fail performance obtained in IDEB and Prova Brasil, for students of the 5th year (fourth grade) elementary school of municipal and state of São Paulo, considering the typology to the IBGE classification of schools in rural and urban areas and the place of residence of the students as a way to characterize the level of rural schools. Work organized a diagnosis of ongoing policies; suggests some guidelines for the improvement of future interventions in this area of government action and, shows that in many situations, the performance of schools "rural" considering the items analyzed is lower than the performance of schools urban.

Keywords: educational policy, education, public school, development indicator, rural school

\section{Introdução}

Considerando a educação escolar um requisito para o desenvolvimento, Kliksberg (1998) afirma que investimentos em capital humano, capital social e melhoria da equidade, em uma perspectiva democrática, são primordiais para formar bases firmes ao crescimento econômico. Dessa forma, são necessárias iniciativas que assegurem um ensino de qualidade aos alunos que dependem do sistema público e gratuito (ALVES; PASSADOR, 2011). No caso brasileiro, o desenvolvimento e a abrangência da educação ainda apresentam fragilidades, uma vez que a preocupação de promover o desenvolvimento integral da sua população não foi priorizada durante vários anos, o que gerou disparidades consideráveis entre o Brasil econômico e o Brasil social.

Entre os direitos sociais garantidos pela Constituição Brasileira (BRASIL, 1988), a educação ocupa papel de destaque por ser primordial ao exercício da cidadania. Dessa forma, torna-se necessário que o Estado ofereça boas condições educacionais para todos os brasileiros. Contudo, o cumprimento dessa obrigação é, muitas vezes, negligenciado, havendo milhões de brasileiros com acesso precário a esse direito, entre os quais, destaca-se grande parcela da população 
rural (BAPTISTA, 2003). Segundo a Pesquisa Nacional por Amostra de Domicílios PNAD (IBGE, 2009), os analfabetos brasileiros somam 14,1 milhões de pessoas acima de 15 anos, sendo $40 \%$ destes no meio rural.

Frente ao quadro exposto e à efervescência dos movimentos sociais, o Governo Federal realizou parcerias com vários ministérios, criando projetos na área em questão. Entre eles, a aprovação das Diretrizes Operacionais para a Educação Básica nas Escolas do Campo (2001), que, na explicação de Canário (2000), sugerem que a escola precisa estar em sintonia com as mudanças ocorridas no meio, com as tecnologias criadas e aperfeiçoadas e as expectativas que se formam de acordo com o modo de vida e de trabalho que está em transformação como o aluno.

O espaço rural arraiga problemas que não são somente de disparidade de investimentos e políticas públicas voltadas somente para o espaço urbano, mas também de uma desigualdade gerada por anos de história (Abramovay, 2000; Veiga, 2002). Mesmo que ainda exista uma notável porcentagem de pessoas analfabetas no Brasil, atualmente existem projetos que tentam mudar esse cenário. Oliveira (2008) revela que, recentemente, o Governo Federal, por meio de parceria com vários ministérios e com movimentos ligados à luta do campo, lançou alguns programas e projetos para a educação da população rural.

Ainda que não seja uma solução permanente, as iniciativas, tanto federais quanto estaduais para a educação do campo ${ }^{1}$, tentam romper com a negligência existente no País quanto a essa área no passado. Porém, é necessário dizer que, mesmo que ações estejam sendo promovidas, ainda há muito a evoluir.

Assim, este trabalho tem como objetivo central apresentar uma retrospectiva histórica e as tendências das políticas públicas de educação do campo no Brasil, além de analisar a influência da localização da escola e a origem dos alunos (rural e urbano) na taxa de evasão, na taxa de aprovação/reprovação, no desempenho no IDEB e na Prova Brasil. Para tanto, foram analisados os alunos do 50 ano (quarta série) do ensino fundamental das redes municipal e estadual do Estado de São Paulo. A tipologia do IBGE para classificação das escolas em rurais e urbanas e o local de moradia dos alunos foram utilizados como forma de caracterizar o nível de ruralidade das escolas.

1 Atualmente há diversos debates em torno dos termos "educação no campo", "educação rural" e "educação do campo". Os termos não devem ser utilizados indistintamente ou como sinônimos; por tal fato, assumese no presente trabalho o termo "educação do campo" como mais adequado para comportar as particularidades desse âmbito e o histórico de lutas de movimentos sociais em prol de uma educação contextualizada. 
A proposta justifica-se na medida em que culmina em um quadro-síntese interessante para acadêmicos e gestores públicos, ademais de conectar eventos e fatores contextuais com os avanços da educação do campo no Brasil, principalmente a partir da Constituição de 1988. À continuidade, encontramse uma seção sobre a evolução das políticas públicas de educação do campo; um quadro-síntese que relaciona o contexto histórico da educação no Brasil com a transformação da "educação rural" para a "educação do campo"; a metodologia utilizada; a análise dos dados no Estado de São Paulo; e as considerações finais.

\section{Políticas públicas de educação do campo}

A modalidade de ensino agrícola no Brasil originada no século XIX, durante o período da República Velha, demonstrou, em seu desenvolvimento, o surgimento de ações as quais contemplavam o atendimento das necessidades surgidas durante a evolução do sistema econômico brasileiro. Ressalta-se a existência de iniciativas educacionais no período em questão, como a criação de institutos agrícolas entre 1859-1861, o financiamento de escolas primárias e escolas rurais, por exemplo.

No entanto, é a partir de 1930 que "[...] os órgãos oficiais começaram a demonstrar interesse pela educação rural, tendo como principal preocupação a questão do êxodo rural" (PASSADOR, 2006). Nesse período, há a criação do Ministério da Educação e a garantia de financiamento do ensino rural por meio da Constituição de 1934 (BrasIL, 1934). Também como exemplo, há a Constituição de 1946 (BRASIL, 1946), a qual promovia a educação como direito de todos, mantendo as empresas como responsáveis pelo ensino na área rural.

Em 1952, foi criada a Campanha Nacional de Educação Rural (CNER)², oficializada somente em 1956 (Governo Juscelino Kubitschek) e extinta poucos anos depois, em 1963. Tinha por objetivo estimular, por meio da educação de base, a adequação da população que vivia no campo ao plano de desenvolvimento econômico. A época em que a campanha foi criada, a década de 1950, foi permeada pela ideia de desenvolvimento industrial, e isso impactou a realidade da agricultura e da população que vivia no campo. O fundamento da

2 A execução da CNER ficou a cargo da Associação Brasileira de Assistência Técnica e Extensão Rural (ABCAR) e o modelo adotado seguiu a experiência extensionista dos Estados Unidos. Não foram feitas adaptações ao "pacote" que havia sido testado no país-metrópole, realizando-se um transplante cultural da aplicação da política. 
criação da campanha ganhou força nas correntes filosóficas e ideológicas que discutiam o desenvolvimento econômico, cultural e social das populações mais pobres, com o objetivo de integrá-las ao modelo de desenvolvimento e modernização, incluindo o meio rural no processo de expansão industrial da década de 1950. Por se tratar de um modelo desenvolvido pelos líderes do governo, a CNER, ao "educar" a população, transformava-se em um "passaporte" para a vida urbana, uma vez que os conhecimentos transformariam o homem do campo em um sujeito inadaptado ao seu meio e a solução seria buscar a cidade (Calazans; Castro; Silva, 1981).

Nota-se nesses primeiros passos que há no Brasil, em decorrência da estrutura fundiária fruto do modelo econômico agroexportador inicialmente desenvolvido, a não necessidade de mão de obra especializada, não sendo necessária a formulação de políticas públicas na área da educação para a população. Até então, o objetivo era apenas a qualificação educacional da elite brasileira (GRITTI, 2007; SIIVA, 2004). De maneira geral, ao longo da história brasileira, registra-se um período de abandono por parte do Estado no que diz respeito à oferta da educação no meio rural (MoLINA, 2010; Molina, Montenegro; Oliveira, 2010).

Entretanto, o cenário da educação rural foi drasticamente modificado na década 1960 com a promulgação da Lei no 4.024 (BRASIL, 1961). Nessa lei, vários fatores relacionados à educação brasileira foram alterados com foco, majoritariamente, na educação urbana. A educação rural, por sua vez, foi deixada a cargo das municipalidades, sem considerar que as prefeituras municipais do interior não possuíam recursos humanos e financeiros para estruturar a oferta. A partir disso, evidencia-se o processo de deterioração da educação rural e a submissão ao modelo urbano (Leite, 2002).

O Golpe Militar de 1964 também representou mudanças no cenário da educação no Brasil. Foi idealizada uma reforma dos ensinos de primeiro e segundo grau no Brasil, aumentando a obrigatoriedade em termos de anos de estudo, a visão profissionalizante da educação, mas sem se estender para a população rural (SIIVA, 2003). As escolas rurais, por sua vez, continuaram vinculadas às empresas, reduzindo a responsabilidade do governo sobre a educação rural e, consequentemente, excluindo-as dos modelos educacionais que seriam adotados. O ideal de extensão rural, que havia sido enfraquecido anteriormente, voltou a tomar força, e as professoras do ensino formal do campo foram substituídas por técnicos e extensionistas, que eram financiados pelas empresas.

Por outro lado, nos anos 1960, intensificou-se o processo de industrialização da agricultura, denominado "Revolução verde". Como característica do movimento, há o desenvolvimento de forças produtivas do campo, as quais ansiavam pelo 
aumento da produtividade baseado em insumos, como adubos, fertilizantes, inseticidas, máquinas e implementos agrícolas (FeItosA, 2007). A reestruturação da agricultura torna-se, juntamente com os aspectos de urbanização e intensificação industrial, fator importante na implantação de políticas educacionais para a população rural (GrıTTI, 2007). Como exemplo, tem-se a Lei de Diretrizes e Bases da Educação - LDB no 4.024/61 e as Reformas da LDB referentes ao ensino superior, no 5.540/68, e ao ensino primário, no 5.692/71. Nestas, o trabalhador camponês é visto como um instrumento de produção, e não como protagonista de um projeto social global (Coutinho; Teixera, 2009). Pode-se citar também como exemplo a elaboração do Plano de Desenvolvimento do Ensino Agrícola de 2 o grau, o qual afirma que:

[...] através de cursos profissionalizantes, as escolas de 20 grau deverão preparar pessoal qualificado contribuindo para:

- melhorar os níveis de produtividade;

- promover especialistas para melhorar a distribuição de renda no meio rural;

- propiciar o eficiente suprimento de produtos agrícolas para um crescente mercado interno;

- garantir o aumento de capital e mão de obra para o desenvolvimento econômico geral;

- promover a integração econômica e social pela ampliação da capacidade de absorção de produtos não agrícolas. (BRASIL, 1973).

No contexto da implantação de políticas educacionais da educação do campo, a construção de novas ações educacionais dá-se no final da década de 1980, quando os incipientes movimentos sociais protagonizam o novo projeto de sociedade e educação, promovendo novos valores, identidades e consciência para os povos do campo, a fim de transformarem suas realidades e o atendimento dos seus direitos estabelecidos (Coutinho; Teixeira, 2009; Paraná, 2009). Tal comportamento era reflexo de uma consolidação do modelo de industrialização que vinculava o desenvolvimento à área urbana e restringia o campo à produção agrícola, que atendia ao modo de produção capitalista, limitando-se ao desenvolvimento do agribusiness e à manutenção dos latifúndios. Nesse cenário, a população rural em essência e ligada à agricultura familiar foi desamparada de políticas que buscassem atender aos seus interesses (Calazans; Castro; Silva, 1981).

O período de redemocratização, que ocorreu no final dos anos 1980 e início de 1990, marcava também uma nova mudança de conjuntura no País e, com isso, 
mudanças no modelo de governo e na atenção direcionada para a educação. Com a Constituição de 1988 (BRASIL, 1988), a educação passou a ser um direito de toda a população e dever do Estado. Já na década de 1990, as discussões a respeito da LDB incluíram normas específicas para a educação do campo. Nessa lei, a educação rural foi desvinculada da escola urbana e tornou-se passível de adequação à realidade do campo (com calendário e número de horas diferenciados), favorecendo a escolaridade de acordo com a sazonalidade agrícola.

Recentemente, dois processos políticos foram desenvolvidos para a educação e possuem implicações sobre a educação do campo. O primeiro deles é o Plano Nacional de Educação (PNE), aprovado pelo Congresso Nacional em 2001. As críticas a essa política consistem no fato de ter sido desenvolvida pelo poder público, não contemplando a realidade dos problemas da educação do campo e, consequentemente, não atendendo às metas de qualidade da educação requeridas pelo Movimento de Educação do Campo, sendo unilateral e excludente (MunARIM, 2008b). O segundo processo político foi a elaboração das diretrizes operacionais. Sua elaboração contou com encontros, reuniões e audiências públicas, nas quais havia autores participantes sensíveis ao Movimento de Educação do Campo (Munarim, 2008b). Um ponto a se ressaltar no contexto das diretrizes operacionais é em relação ao modelo de governo vigente no momento em que foram elaboradas e aprovadas. A eleição do presidente Luiz Inácio Lula da Silva, em 2002, consistia na posse de um governo sensível aos movimentos sociais, entre eles, o Movimento de Educação do Campo.

Nesse período, foi estabelecido o Programa Nacional de Educação na Reforma Agrária (Pronera), que assegurava o comprometimento de governos futuros com a criação de cursos de Pedagogia e de especialização específicos para professores das escolas do campo. Assim, Martins (2010) e Munarim (2008a) destacam a emergência, a partir da década de 1990, de um movimento social chamado "Por uma Educação do Campo". O movimento objetiva a criação de políticas públicas que renovem a chamada educação rural, atribuindo-lhe níveis de qualidade e fugindo da ideia de exclusão e domesticação da população que vive no campo.

A Nova Lei de Diretrizes e Bases da Educação (LDBEN) tornou-se ativa pouco depois do estabelecimento da Constituição de 1988 (BRASIL, 1988), focando, entre outros aspectos, a educação infantil e a educação do campo. O primeiro texto de projeto da LDBEN passou pela Câmara dos Deputados ainda em 1988, mas só se tornou ativo nos aspectos relativos à educação do campo e educação infantil em 1996. 
Porém, somente em 2004, o Ministério da Educação criou a Secretaria de Educação Continuada, Alfabetização e Diversidade (Secad), que tem, entre suas atribuições, a de gerenciar diversos programas voltados à melhoria das condições de ensino do campo. Seus principais temas de trabalho são: alfabetização, educação do campo, educação ambiental, educação em direitos humanos e educação escolar indígena. O objetivo da secretaria é reduzir as desigualdades educacionais por meio de políticas públicas de ampliação da educação.

Em 2011, o MEC incluiu a questão da inclusão social na pauta da Secad e a mesma passou a ser denominada de Secretaria de Educação Continuada, Alfabetização, Diversidade e Inclusão - Secadi (BRASIL, 2011b). Entre os programas da Secadi, verificamos o Escola Ativa, com metodologia voltada para salas multisseriadas. Outra iniciativa, de abril de 2009, é o Programa de Apoio à Formação Superior em Licenciatura em Educação do Campo (Procampo), que tem como objetivo investir na formação de professores dos anos finais do ensino fundamental (BRASIL, 2011a). O programa Procampo iniciou-se em 2005, com quatro pilotos em universidades federais situadas em Belo Horizonte (MG), Brasília (DF), Salvador (BA) e Aracajú (SE), que hoje já formaram as primeiras turmas de discentes em educação do campo. Há também o Projovem Campo - Saberes da Terra, que oferece qualificação profissional e escolarização a jovens agricultores familiares que não concluíram o ensino fundamental.

É necessário reafirmar que o conceito de educação do campo é muito recente, sendo assim, pode-se destacar como uma das primeiras iniciativas o "I Encontro Nacional de Educadoras e Educadores da Reforma Agrária", em 1997. Em 1998, foi feita a Conferência Nacional "Por uma Educação Básica do Campo" (CNEC) que, segundo Vendramini (2007), ajudou a legitimar a luta por políticas públicas específicas e por projetos voltados para a população do campo.

Entretanto, conforme dados disponibilizados por Baptista (2003), a forma de atuação da educação do campo só foi formalizada em 2002, por meio das Diretrizes Operacionais para Educação Básica nas Escolas do Campo, e tratada pela Resolução no 01, de 3 de abril de 2002, da Câmara de Ensino Fundamental do Conselho Nacional de Educação.

Em resumo, na tentativa de reverter o quadro de analfabetismo, o Governo Federal, em parceria com os vários ministérios e com movimentos ligados à luta do campo, lançou alguns programas e projetos para a educação da população rural. Em 1996, foi criada a nova LDB - Lei no 9.394 (BRASIL, 1996), sendo a primeira lei que aborda a educação rural (ver artigo 28, da LDB). 
Essa nova discussão em torno das políticas públicas voltadas para o campo gerou mobilizações em universidades públicas e municípios brasileiros a fim de debater diretrizes para a educação do campo e proposições que se adequassem à vida da população rural. Como resultado das discussões ocorridas, as "Diretrizes Operacionais para a Educação Básica nas Escolas do Campo" foram aprovadas. A resolução concretiza o direito à educação da população rural tendo em vista a realidade local, contextualizando o ensino.

Na II Conferência Nacional "Por uma Educação do Campo", em 2004, o principal tema foi especificar políticas públicas de educação do campo, tendo o País um histórico de políticas generalistas. Segundo Arroyo (2007), os movimentos sociais do campo avançaram na defesa do direito a políticas públicas. Molina (2010) diz que a criação da Secadi teve influência direta da "II Conferência Nacional". O estabelecimento da secretaria foi, de certa forma, a resposta do governo para as iniciativas que vinham sendo tomadas na direção de uma educação melhor, inclusive, para as populações consideradas como minorias.

\section{Quadro-síntese da educação do campo no Brasil}

Em consonância com o surgimento e o fortalecimento de movimentos sociais que demandam adequação da educação do campo à realidade de seus indivíduos e à resposta do governo com a criação de legislação e políticas públicas voltadas para esse público, aumenta também o interesse acadêmico no tema. Passa a ser fortalecida a vertente de pesquisa que parte da premissa de que, no tocante à educação rural, é preciso considerar, no conjunto dos saberes historicamente produzidos, aqueles saberes gerados pelos atores sociais em suas práticas produtivas e políticas, tendo em vista que esses saberes têm especificidades em virtude das diversificadas condições de vida e trabalho (Damasceno; Beserra, 2004).

A pesquisa e a produção acadêmica, entretanto, ainda são carentes de sistemas relativos à formulação de políticas específicas e de organização de modelos e aparatos de gestão das mesmas. Simultaneamente, percebe-se a necessidade de discutir a questão da educação do campo relacionada ao contexto do que se entende por "campo" ou área rural no País.

A partir do cenário discutido, o Quadro 1 relaciona as mudanças ocorridas ao longo dos séculos XX e XXI na educação, no Brasil, e o impacto das alterações no cenário da educação do campo. 


\section{Quadro 1: Relação entre a educação no Brasil e educação do campo}

\begin{tabular}{|c|c|c|}
\hline & Contexto histórico da educação no Brasil & $\begin{array}{l}\text { Contexto da transformação da educação rural } \\
\text { para educação do campo no Brasil }\end{array}$ \\
\hline 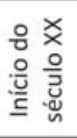 & $\begin{array}{l}\text { - Educação elitista - Jesuítas } \\
\text { - 1930: Criação do Ministério da Educação - } \\
\text { responsabilidade do Estado em prover educação } \\
\text { pública. }\end{array}$ & $\begin{array}{l}\text { - Início da educação rural, em 1889, por meio } \\
\text { da Pasta de Agricultura, Comércio e Indústria. } \\
\text { - Surgimento do ruralismo pedagógico: visava } \\
\text { fixar o homem ao campo. }\end{array}$ \\
\hline 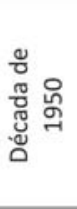 & $\begin{array}{l}\text { - Educação definida conforme o modelo nacional } \\
\text { desenvolvimentista. } \\
\text { - Mecanismo para o desenvolvimento objetivava a } \\
\text { modernização da sociedade e a formação de } \\
\text { recursos humanos. }\end{array}$ & $\begin{array}{l}\text { - Surgiu a Campanha Nacional de Educação Rural } \\
\text { (CNER). } \\
\text { - Objetivo: estimular, por meio da educação de } \\
\text { base, a adequação da população que vivia no } \\
\text { campo ao plano de desenvolvimento } \\
\text { econômico. }\end{array}$ \\
\hline 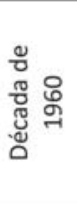 & $\begin{array}{l}\text { - Lei no } 4.024 \text { de 1961: preservação da educação } \\
\text { nacional urbana e voltada para as classes } \\
\text { dominantes. } \\
\text { - Descentralização para os estados dos ensinos } \\
\text { primário e médio. }\end{array}$ & $\begin{array}{l}\text { - Deterioração da educação rural brasileira: Lei } \\
\text { no } 4.024 \text { de } 1961 \text {. } \\
\text { - Educação rural- cargo das municipalidades - } \\
\text { desconsiderava que as prefeituras municipais } \\
\text { do interior não possuíam recursos humanos e } \\
\text { financeiros para estruturar a educação rural. }\end{array}$ \\
\hline 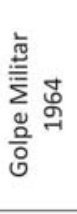 & $\begin{array}{l}\text { - Expansão do acesso ao ensino médio, no } \\
\text { entanto, privilegiando a população urbana. } \\
\text { - Foco no modelo desenvolvimentista. }\end{array}$ & $\begin{array}{l}\text { - Escolas rurais vinculadas a empresas (tirou a } \\
\text { responsabilidade do governo). } \\
\text { - Modelo de extensão rural voltou a tomar } \\
\text { forças e as professoras do ensino formal do } \\
\text { campo foram substituídas por técnicos e } \\
\text { extensionistas financiados pelas empresas. }\end{array}$ \\
\hline 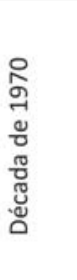 & $\begin{array}{l}\text { - Educação para o desenvolvimento. } \\
\text { - Viés centralizador pela esfera federal: visava } \\
\text { ampliar o acesso pela expansão da rede de } \\
\text { ensino. } \\
\text { - Repressão aos movimentos estudantis. } \\
\text { - Desenvolvimento do primeiro, segundo e } \\
\text { terceiro grau no Pais, buscando formar quadros } \\
\text { científicos e tecnológicos. }\end{array}$ & $\begin{array}{l}\text { - Políticas públicas voltadas para a educação } \\
\text { rural muito precárias; em algumas regiões do } \\
\text { País, era comum o Estado prover o transporte } \\
\text { dos alunos para as escolas urbanas ou escolas } \\
\text { "núcleo". O cenário de baixa atenção às } \\
\text { políticas públicas de educação rural a partir da } \\
\text { década de } 1960 \text { - } 1980 \text { reforçou-se com o } \\
\text { aumento dos índices de êxodo rural na época. }\end{array}$ \\
\hline 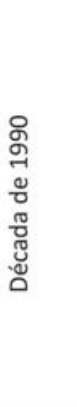 & $\begin{array}{l}\text { - Crise econômica, social e fiscal. } \\
\text { - Desintervencionismo estatal. } \\
\text { - Reforma administrativa do governo. } \\
\text { - LDB (1996): priorização do ensino fundamental e } \\
\text { busca por aumento de vagas. } \\
\text { - Responsabilização da educação aos Estados e } \\
\text { Municípios (descentralização) sem o respectivo } \\
\text { respaldo financeiro para ampliação de vagas. } \\
\text { - Universalização do ensino no fim do século XX: } \\
\text { política de redução do investimento público em } \\
\text { educação. } \\
\text { - Queda no nível de qualidade da educação. }\end{array}$ & $\begin{array}{l}\text { - Mudança no cenário rural: "novo mundo } \\
\text { rural”: determinação de limites entre o } \\
\text { ambiente rural e urbano tornou-se complexa. } \\
\text { - LDB regularizou adequações necessárias à } \\
\text { educação rural. }\end{array}$ \\
\hline 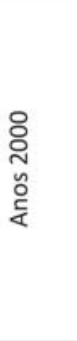 & $\begin{array}{l}\text { - Emergência de políticas públicas participativas } \\
\text { - Novos processos de avaliação da educação } \\
\text { básica pelo Inep. } \\
\text { - Criação do Observatório Nacional da Educação } \\
\text { em } 2002 \text {. }\end{array}$ & $\begin{array}{l}\text { - Movimento social “Por uma Educação do } \\
\text { Campo". Constituído pelos sujeitos sociais do } \\
\text { campo, objetiva criar políticas públicas que } \\
\text { visem renovar a chamada educação rural pela } \\
\text { educação do campo. } \\
\text { - Criação da Secadi em } 2004 \text {. } \\
\text { - Propõe incorporação do modo de vida do } \\
\text { campo, aspectos culturais, sua organização } \\
\text { própria de política, trabalho. } \\
\text { - Projovem Saberes da Terra. }\end{array}$ \\
\hline
\end{tabular}

Fonte: Elaborado pelos autores. 


\section{Aspectos metodológicos}

Quanto à abordagem, este estudo é classificado como misto. Qualitativo quando analisa situação complexa - evolução das políticas públicas para a educação do campo - com vistas a compreender e classificar os processos de determinados grupos e proporcionar o entendimento de alguns fatores do comportamento dos indivíduos. Quantitativo, pois se utiliza de métodos de mensuração e quantificação para a coleta e tratamento de dados - Prova Brasil -, utilizando-se de técnicas estatísticas, com o intuito de garantir precisão às análises e permitir a realização de inferências (RICHARDSON, 1999).

Este estudo é classificado ainda como exploratório, quando se busca maior familiaridade com o tema (HAIR JR et al., 2006), ao buscar mais especificamente uma melhor compreensão sobre a forma como a educação rural é conduzida no Brasil atualmente; e descritivo, pois tem como preocupação central a descrição de características de determinada população ou fenômeno, e o estabelecimento de relações entre variáveis, por meio da mensuração dos eventos (GIL, 2002).

Em princípio, realizou-se um levantamento bibliográfico, visando apresentar uma retrospectiva histórica a partir das políticas públicas de educação do campo no Brasil. Posteriormente, utilizou-se o critério do IBGE para classificação das escolas urbanas e rurais, sendo estas escolas localizadas fora dos perímetros urbanos; e um segundo critério, considerando a proporção de alunos das escolas que são moradores da zona rural em relação ao total de alunos da escola, aqui denominado de índice de ruralidade da escola.

Os dados utilizados neste estudo são referentes ao desempenho das escolas na Prova Brasil (edição 2009), à pontuação no Índice de Desenvolvimento da Educação Básica (IDEB) de 2009, e dados de aprovação, reprovação e abandono escolar do mesmo ano, disponíveis em bancos de dados de indicadores educacionais do Instituto Nacional de Estudos e Pesquisas Educacionais Anísio Teixeira (INEP).

Para análise dos dados, foi utilizada a estatística descritiva e a estatística inferencial, mais especificamente médias, medianas, análises de frequências, testes para diferenças de médias e representação gráfica dos dados, como forma de resumir uma grande quantidade de dados e mostrar seu comportamento. Com essas análises, pretendeu-se criar uma visão geral dos dados obtidos. 
Para definir a significância do resultado obtido no presente estudo, optou-se por considerar o nível de significância de $95 \%$, ou seja, os resultados obtidos precisam ter uma significância menor que 0,05 (á < 0,05) para serem considerados significativos.

No presente estudo, o objetivo dos testes de significância é verificar se as diferenças de médias observadas entre os grupos são estatisticamente significantes. Para tanto, realizaram-se os testes: teste $\mathrm{T}$, o teste Anova e o teste de Bonferroni.

Vale ressaltar que, embora o trabalho tenha sido desenvolvido utilizando-se a população, o que dispensaria os testes estatísticos para avaliação das diferenças das médias, optou-se por realizar esses testes, pois, em alguns casos, as variáveis para algumas escolas ou estavam ausentes ou estavam inconsistentes e, portanto, tratou-se essa população como sendo uma amostra.

\section{Caracterização da população e da amostra}

No ano de 2009, 9.838 escolas municipais e estaduais do Estado de São Paulo - a população total - participaram do censo escolar, conforme se observa na Tabela 1. Nesta tabela, é possível visualizar a quantidade de escolas sob a responsabilidade de cada nível administrativo do governo e, também, a localização das escolas. Notase que a participação municipal na composição do quadro escolar de educação básica no Estado de São Paulo é predominante, tanto em área urbana como em área rural.

Pode-se observar que, das escolas participantes do censo escolar, apenas uma parte realizou a Prova Brasil. Essa participação se deve ao fato de que, para participar da referida prova, a escola deveria ter no mínimo 20 alunos matriculados na série avaliada. Assim, para esse estrato da população total, a

Tabela 1: Quantidade de escolas da educação básica que responderam ao censo escolar, número de escolas que participaram da Prova Brasil (PB) e quantidade de alunos (matrículas PB) que participaram da Prova Brasil, por rede e localização da escola

\begin{tabular}{l|c|c|c|c|c|c|c|c}
\hline \multirow{2}{*}{ Rede } & \multicolumn{4}{|c|}{ Urbana } & \multicolumn{4}{c}{ Rural } \\
\cline { 2 - 9 } & Censo & Participação na Prova Brasil (PB) & Censo & \multicolumn{2}{c}{ Participação na Prova Brasil (PB) } \\
\cline { 2 - 9 } & $\begin{array}{c}\text { Qtd. } \\
\text { Escolas }\end{array}$ & N & $\%$ & $\begin{array}{c}\text { Qtd. } \\
\text { Escolas }\end{array}$ & $\begin{array}{c}\text { Qtd. } \\
\text { Escolas }\end{array}$ & N & $\%$ & $\begin{array}{c}\text { Qtd. } \\
\text { Alunos }\end{array}$ \\
\hline Estadual & 4.716 & 1.845 & 39,1 & 264.688 & 286 & 65 & 22,7 & 3.198 \\
\hline Municipal & 5.122 & 3.812 & 74,4 & 439.429 & 958 & 235 & 24,5 & 9.567 \\
\hline Total & 9.838 & 5.657 & 57,5 & 704.117 & 1.244 & 300 & 24,1 & 12.765 \\
\hline
\end{tabular}

Fonte: Prova Brasil 2009 e Censo Escolar 2009 
análise é censitária, delimitando a população em estudo. Esta população em estudo, por motivos já discutidos anteriormente, foi tratada como sendo uma amostra. A participação das escolas urbanas foi de $57,5 \%$ e das escolas rurais, $24,1 \%$. A participação relativa e absoluta das escolas municipais na Prova Brasil foi bem superior em relação à participação das escolas estaduais. Contudo, vale ressaltar que as escolas rurais começaram a participar da prova nesta edição (2009).

Quando se observa a relação entre alunos participantes da Prova Brasil e o número de escolas, constata-se que a relação entre alunos (matrículas) por escolas do campo é muito inferior à relação urbana, sugerindo a quantidade elevada de escolas do campo com menos de 20 alunos matriculados na série a ser avaliada e, portanto, não atendendo ao requisito mínimo de participação na prova. Por isso, a baixa participação das escolas rurais.

Essa análise permite também evidenciar um fator que pode ser motivador da redução da quantidade de escolas nas áreas rurais; trata-se do maior custo por aluno devido à falta de escala. Molina, Montenegro e Oliveira (2010) discutem o tema, caracterizando a rede de ensino no meio rural como composta por estabelecimentos de pequeno porte e que, nos últimos anos, vem-se reduzindo drasticamente devido às políticas de nucleação das escolas e transporte escolar.

Ao analisar o porte das escolas do Estado de São Paulo - Figuras 1 e 2 -, a afirmação desses autores encontra suporte. As escolas localizadas em área rural apresentam menor quantidade de alunos, sendo a grande maioria escolas com até 200 alunos e, portanto, de menor porte. Já as escolas da área urbana apresentam um perfil mais variado, havendo escolas com poucos alunos e escolas com muitos alunos.

Analisando os dados da Figura 2 e das Tabelas 2 e 3, pode-se observar claramente a diferença de porte das escolas urbanas e rurais, tanto para a rede estadual quanto para a rede municipal. Em média, as escolas estaduais urbanas têm 801 alunos e as escolas estaduais rurais, 379 alunos. Enquanto na localização urbana mais de $25 \%$ (terceiro quartil) das escolas estaduais têm mais de 1 mil alunos, apenas $5 \%$ das escolas estaduais rurais têm mais de 1 mil alunos. Em relação às escolas municipais, as escolas urbanas têm em média 647 alunos, enquanto as escolas rurais têm em média 220 alunos. Enquanto 17\% das escolas municipais urbanas têm mais de 1 mil alunos, nenhuma das escolas municipais rurais tem mais de 1 mil alunos. A maior escola municipal rural tem 861 alunos, sendo que 95\% dessas escolas têm menos de 500 alunos. 


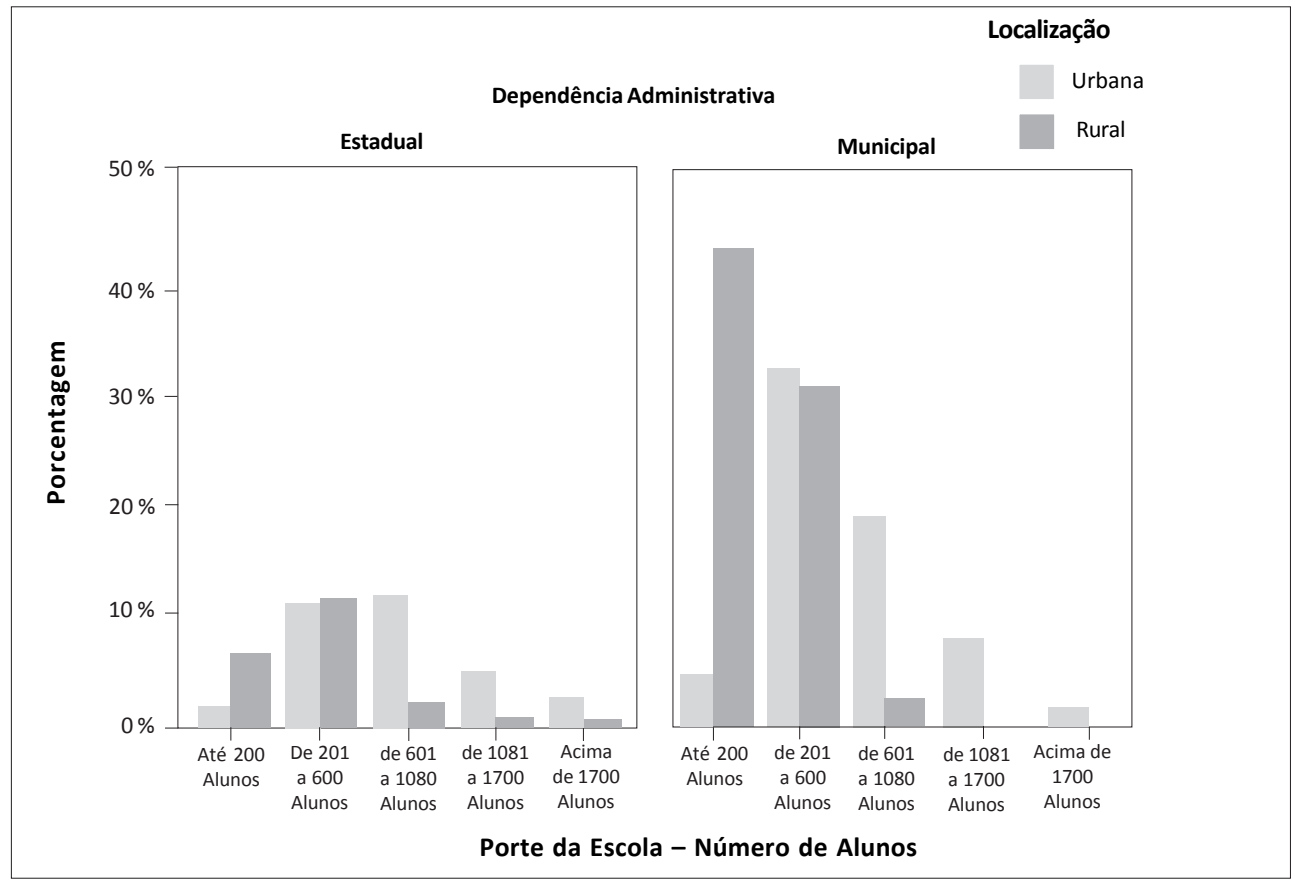

Fonte: Prova Brasil 2009 e Censo Escolar 2009.

\section{Figura 1: Porte das escolas (número de alunos) por localização e rede}

Com o objetivo de avaliar se a quantidade média de alunos por escola, tanto das redes municipais como estaduais, localizadas em áreas urbanas ou rurais, era estatisticamente diferente, utilizou-se o teste $\mathrm{T}$ para diferença de médias. Conforme dito anteriormente, os resultados mostram, com significância de 0,001, que, em média, as escolas municipais têm menos alunos que as escolas estaduais, e as escolas localizadas em área rural têm menos alunos, conforme se observa nas Tabelas 2 e 3.

Para analisar o índice de ruralidade da escola, utilizou-se o local de moradia dos estudantes a partir do censo escolar. Esse índice foi calculado dividindo a quantidade de alunos residentes na zona rural pela quantidade total de alunos. Os grupos formados são apresentados na Tabela 4. Conforme se observa, a grande maioria das escolas - $86 \%$ das escolas estaduais e $72 \%$ das escolas municipais são escolas localizadas em zonas urbanas com baixa presença (até 20\%) de alunos residentes em zonas rurais.

\section{Discussão dos resultados}

Analisando o desempenho dos alunos e das escolas da rede estadual de ensino do Estado de São Paulo (Tabela 5), observa-se que tanto as escolas localizadas em 

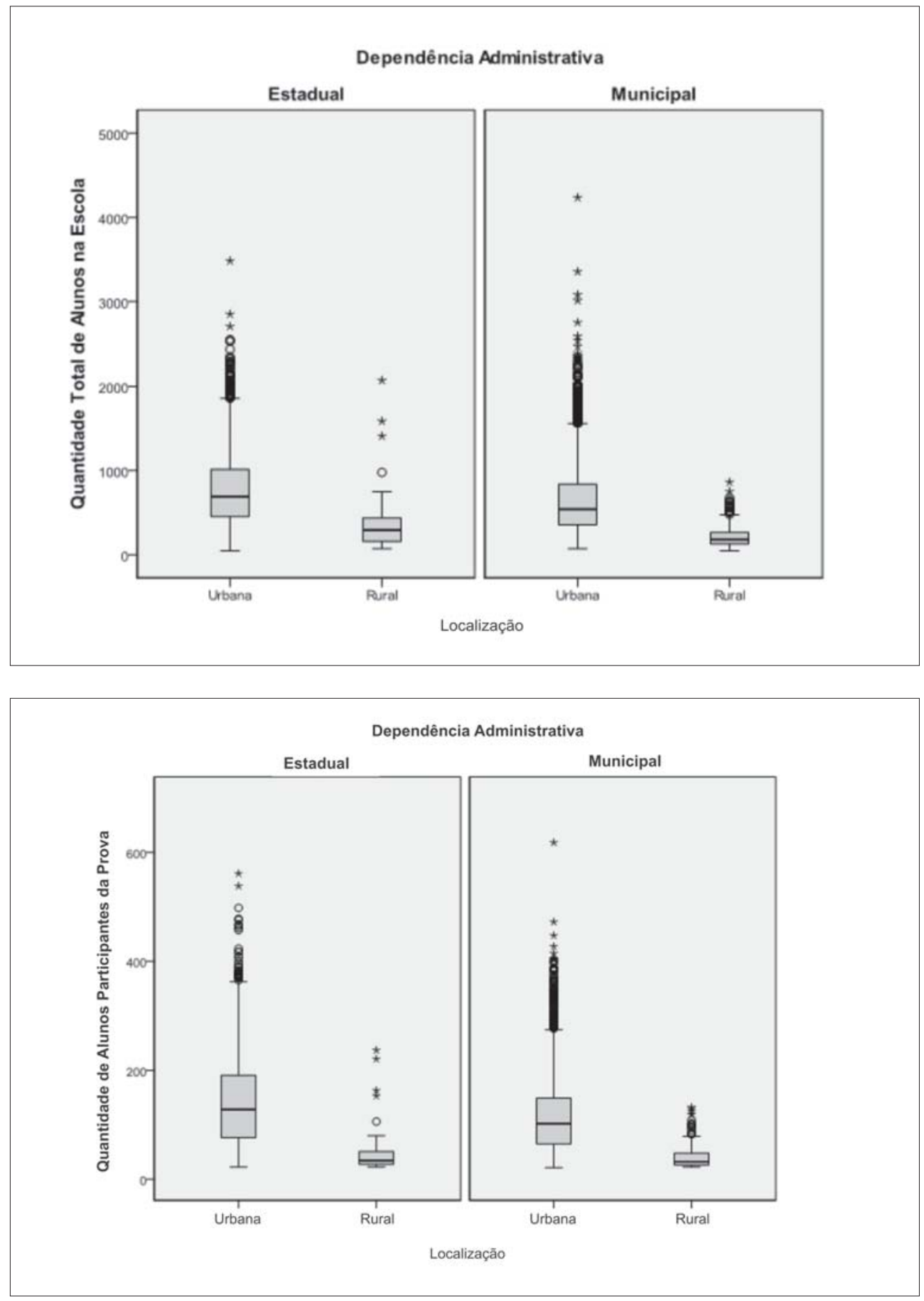

Fonte: Prova Brasil 2009 e Censo Escolar 2009.

Figura 2: Quantidade de alunos por escola, por localização e por rede 
Tabela 2: Porte da escola - Rede X Localização - Número de alunos

\begin{tabular}{|c|c|c|c|c|c|}
\hline Rede & Localização & № Escolas & $\begin{array}{l}\text { Média } \\
\text { Alunos }\end{array}$ & $t$ & sig \\
\hline \multirow{2}{*}{ Estadual } & Urbano & 1844 & 800,86 & \multirow{2}{*}{9,33} & \multirow{2}{*}{, 00} \\
\hline & Rural & 65 & 378,71 & & \\
\hline \multirow{2}{*}{ Municipal } & Urbano & 3811 & 646,57 & \multirow{2}{*}{38,55} & \multirow{2}{*}{,00 } \\
\hline & Rural & 235 & 219,50 & & \\
\hline
\end{tabular}

Fonte: Censo Escolar 2009.

Tabela 3: Porte da escola - Localização X Rede - Número de alunos

\begin{tabular}{c|c|c|c|c|c}
\hline \multirow{2}{*}{ Localização } & Rede & No Escolas & $\begin{array}{c}\text { Média } \\
\text { Alunos }\end{array}$ & t & sig \\
\hline \multirow{2}{*}{ Urbano } & Estadual & 1844 & 800,86 & \multirow{2}{*}{11,71} & \multirow{2}{*}{00} \\
\cline { 2 - 4 } & Municipal & 3811 & 646,57 & & \multirow{2}{*}{00} \\
\hline \multirow{2}{*}{ Rural } & Estadual & 65 & 378,71 & \multirow{2}{*}{3,57} & \\
\cline { 2 - 4 } & Municipal & 235 & 219,20 & & \\
\hline
\end{tabular}

Fonte: Censo Escolar 2009.

Tabela 4: Ruralidade das escolas

\begin{tabular}{|c|c|c|c|c|}
\hline \multirow{2}{*}{ Índice de Ruralidade } & \multicolumn{2}{|c|}{ Rede Estadual } & \multicolumn{2}{|c|}{ Rede Municipal } \\
\hline & Qtd & $\%$ & Qtd & $\%$ \\
\hline Só alunos de Área Urbana & 87 & 4,6 & 571 & 14,1 \\
\hline Até $20 \%$ de alunos de Área Rural & 1651 & 86,5 & 2925 & 72,3 \\
\hline De $20 \%$ a $40 \%$ de alunos de Área Rural & 85 & 4,5 & 274 & 6,8 \\
\hline De $40 \%$ a $60 \%$ de alunos de Área Rural & 31 & 1,6 & 89 & 2,2 \\
\hline De $60 \%$ a $80 \%$ de alunos de Área Rural & 18 & 9 & 69 & 1,7 \\
\hline Acima de $80 \%$ de alunos de Área Rural & 37 & 1,9 & 118 & 2,9 \\
\hline Total & 1909 & 100,0 & 4046 & 100,0 \\
\hline
\end{tabular}

Fonte: Elaborado pelos autores, com base nos dados do Censo Escolar 2009.

áreas urbanas quanto as escolas localizadas em áreas rurais têm indicadores de desempenho médios iguais, excetuando-se o desempenho médio na prova de português da Prova Brasil, onde a nota média das escolas urbanas foi de 189,06, contra uma média de 185,01 das escolas rurais (á = 0,05).

Outro indicador cujas médias foram diferentes e estatisticamente significantes (á $=0,05)$ foi a taxa de abandono, em que as escolas localizadas em áreas urbanas tiveram um desempenho pior $(0,26)$ do que as escolas localizadas em áreas rurais $(0,11)$. Entretanto, ressalta-se que (conforme resultados da análise descritiva dos 
dados) o número de escolas estaduais rurais que participaram da Prova Brasil é muito pequeno (65).

Tabela 5: Desempenho médio - Escolas da rede estadual localizadas em área rural e urbana

\begin{tabular}{|c|c|c|c|c|c|c|c|}
\hline \multicolumn{8}{|c|}{ Teste T para diferença de médias - Escolas da Rede Estadual } \\
\hline Indicador & Localização & $\begin{array}{l}\text { Número de } \\
\text { Escolas }\end{array}$ & Média & $\begin{array}{l}\text { Desv. } \\
\text { Padrão }\end{array}$ & $\begin{array}{l}\text { Dif. } \\
\text { Média }\end{array}$ & $\mathrm{t}$ & Sig \\
\hline Matemática & $\begin{array}{c}\text { Urbana } \\
\text { Rural }\end{array}$ & $\begin{array}{r}1845 \\
65\end{array}$ & $\begin{array}{l}213,122 \\
209,931\end{array}$ & $\begin{array}{l}17,501 \\
20,760\end{array}$ & 3,191 & 1,224 & 225 \\
\hline Português & $\begin{array}{l}\text { Urbana } \\
\text { Rural }\end{array}$ & $\begin{array}{r}1845 \\
65 \\
\end{array}$ & $\begin{array}{l}189,060 \\
185,009\end{array}$ & $\begin{array}{l}14,893 \\
17,255\end{array}$ & 4,051 & 2,143 & 032 \\
\hline IDEB & $\begin{array}{c}\text { Urbana } \\
\text { Rural }\end{array}$ & $\begin{array}{r}1844 \\
65 \\
\end{array}$ & $\begin{array}{l}5,322 \\
5,202\end{array}$ & $\begin{array}{l}0,650 \\
0,700\end{array}$ &, 121 & 1,467 & , 143 \\
\hline Aprovação & $\begin{array}{c}\text { Urbana } \\
\text { Rural }\end{array}$ & $\begin{array}{r}1856 \\
65 \\
\end{array}$ & $\begin{array}{l}93,822 \\
93,812\end{array}$ & $\begin{array}{l}5,618 \\
6,558 \\
\end{array}$ & 011 & 016 & 987 \\
\hline Reprovação & $\begin{array}{c}\text { Urbana } \\
\text { Rural }\end{array}$ & $\begin{array}{r}1856 \\
65 \\
\end{array}$ & $\begin{array}{l}5,918 \\
6,081\end{array}$ & $\begin{array}{l}5,518 \\
6,531 \\
\end{array}$ &,- 162 &,- 215 & 831 \\
\hline Abandono & $\begin{array}{l}\text { Urbana } \\
\text { Rural }\end{array}$ & $\begin{array}{r}1856 \\
65\end{array}$ & $\begin{array}{l}, 259 \\
, 108\end{array}$ & $\begin{array}{l}0,693 \\
0,599\end{array}$ & 151 & 2,158 & 034 \\
\hline
\end{tabular}

Fonte: Prova Brasil 2009, Censo Escolar 2009 e Ideb 2009.

Em relação aos alunos e às escolas da rede municipal de ensino do Estado de São Paulo (Tabela 6), observa-se que as escolas localizadas em áreas urbanas têm indicadores de desempenho médios superiores às escolas localizadas em áreas rurais. O desempenho médio das escolas urbanas nas provas de matemática e português, além do Ideb, é superior ao desempenho médio das escolas rurais e estatisticamente significante $(a ́=0,01)$. Apesar de as escolas urbanas terem um desempenho médio em aprovação e reprovação superior às escolas rurais, a diferença entre essas médias não é estatisticamente significante (á $=0,05)$. A diferença entre as médias de abandono também não é estatisticamente significante.

Conforme mencionado na metodologia e na caracterização da amostra, outra análise, considerando o local de moradia do aluno e o desempenho das escolas, foi realizada. Após a definição do índice de ruralidade das escolas, analisou-se o desempenho médio dessas escolas considerando esse índice dividido em seis faixas dentro das redes estaduais e municipais. Para verificar se o desempenho médio das escolas apresentava diferenças e se era estatisticamente significante, procedeu-se ao teste Anova para diferença de médias entre grupos. Conforme se pode observar na Tabela 7, em um nível de significância de 95\% (á =0,05), na rede estadual, apenas a aprovação, a reprovação e o abandono apresentam médias diferentes entre níveis diferentes de ruralidade. Na rede municipal, todos os indicadores apresentam médias diferentes entre níveis de ruralidade. 
Tabela 6: Desempenho médio - Escolas da rede estadual localizadas em área rural e urbana

\begin{tabular}{|c|c|c|c|c|c|c|c|}
\hline \multicolumn{8}{|c|}{ Teste T para diferença de médias - Escolas da Rede Municipal } \\
\hline Indicador & Localização & $\begin{array}{l}\text { Número de } \\
\text { Escolas }\end{array}$ & Média & $\begin{array}{l}\text { Desv. } \\
\text { Padrão }\end{array}$ & $\begin{array}{l}\text { Dif. } \\
\text { Média }\end{array}$ & $\mathrm{t}$ & Sig \\
\hline Matemática & $\begin{array}{c}\text { Urbana } \\
\text { Rural }\end{array}$ & $\begin{array}{r}3.812 \\
235\end{array}$ & $\begin{array}{l}216,701 \\
207,873\end{array}$ & $\begin{array}{l}20,759 \\
18,955\end{array}$ & 8,828 & 6,358 &, 000 \\
\hline Português & $\begin{array}{c}\text { Urbana } \\
\text { Rural }\end{array}$ & $\begin{array}{r}3.812 \\
235\end{array}$ & $\begin{array}{l}192,555 \\
185,089\end{array}$ & $\begin{array}{l}17,051 \\
15,291\end{array}$ & 7,467 & 7,214 &, 000 \\
\hline IDEB & $\begin{array}{c}\text { Urbana } \\
\text { Rural }\end{array}$ & $\begin{array}{r}3.811 \\
235 \\
\end{array}$ & $\begin{array}{l}5,287 \\
4,925 \\
\end{array}$ & $\begin{array}{l}0,719 \\
0,680 \\
\end{array}$ & ,362 & 7,509 & ,000 \\
\hline Aprovação & $\begin{array}{c}\text { Urbana } \\
\text { Rural }\end{array}$ & $\begin{array}{r}3.818 \\
235\end{array}$ & $\begin{array}{l}92,847 \\
91,977\end{array}$ & $\begin{array}{l}6,987 \\
8,018\end{array}$ & 870 & 1,642 & ,102 \\
\hline Reprovação & $\begin{array}{c}\text { Urbana } \\
\text { Rural }\end{array}$ & $\begin{array}{r}3.818 \\
235 \\
\end{array}$ & $\begin{array}{l}6,939 \\
7,751 \\
\end{array}$ & $\begin{array}{l}6,886 \\
7,894 \\
\end{array}$ &,- 812 & $-1,556$ & ,121 \\
\hline Abandono & $\begin{array}{c}\text { Urbana } \\
\text { Rural }\end{array}$ & $\begin{array}{r}3.818 \\
235\end{array}$ & $\begin{array}{l}, 214 \\
, 272\end{array}$ & $\begin{array}{l}0,648 \\
0,890\end{array}$ & $-0,58$ & -997 & ,320 \\
\hline
\end{tabular}

Fonte: Prova Brasil 2009, Censo Escolar 2009 e Ideb 2009.

Tabela 7: Teste Anova para diferença de média entre os grupos de ruralidade

\begin{tabular}{l|c|c|c|c}
\hline \multirow{2}{*}{} & \multicolumn{2}{|c|}{ Rede Estadual } & \multicolumn{2}{c}{ Rede Municipal } \\
\cline { 2 - 4 } & $\mathbf{F}$ & Sig. & $\mathbf{F}$ & Sig \\
\hline Matemática & 1,398 &, 222 & 72,918 &, 000 \\
\hline Lingua Portuguesa & 2,208 &, 051 & 58,320 &, 000 \\
\hline IDEB & 1,471 &, 196 & 51,479 &, 000 \\
\hline Aprovação & 2,787 &, 016 & 45,919 &, 000 \\
\hline Reprovação & 2,840 &, 015 & 42,652 &, 000 \\
\hline Abandono & 2,689 &, 020 & 12,489 &, 000 \\
\hline
\end{tabular}

Fonte: Prova Brasil 2009, Censo Escolar 2009 e Ideb 2009.

Dado que foi encontrada diferença estatística significante entre pelo menos um par de grupos, realizou-se o teste de Bonferroni para identificar entre quais grupos se deu essa diferença. No caso das escolas da rede estadual, observou-se que nas escolas com alto índice de ruralidade (acima de $80 \%$ de alunos residentes em zonas rurais) o índice de aprovação é menor, quando comparado com escolas que só têm alunos residentes em áreas urbanas ou que tenham baixa presença de alunos residentes em áreas rurais (até $40 \%$ de alunos residentes em áreas rurais). Para os outros grupos, não foi encontrada diferença estatística significante entre as médias. Esses resultados se repetem para reprovação, como era de se esperar. Ao se analisar o abandono, a diferença estatística significante se dá entre as escolas estaduais que possuem menos de $20 \%$ de alunos residentes em áreas rurais e as escolas que possuem entre $20 \%$ e $40 \%$ de alunos residentes em áreas rurais. Esses 
resultados podem ser observados na Figura 3. Vale destacar que o número reduzido de escolas em alguns grupos contribui para que as diferenças entre as médias não sejam estatisticamente significantes.

Conforme observado na Tabela 7, as escolas municipais apresentaram diferenças estatisticamente significantes em todos os itens avaliados. Inicialmente, o desempenho das escolas municipais apresenta uma curva interessante, que se repete nas provas de matemática e português e no Ideb, conforme se observa na Figura 4. Verifica-se que o desempenho das escolas municipais que possuem $100 \%$ de alunos da área urbana é bem menor que o desempenho das outras escolas da rede. Ao analisar esse grupo de escolas em maior profundidade, percebe-se que $67 \%$ (381) dessas são escolas do Município de São Paulo, 10\% (59) são escolas do Município de Guarulhos, outros $10 \%$ das escolas estão nos municípios que compõem a região metropolitana de São Paulo, e o restante das escolas está pulverizado em todo o estado. Observa-se, também, que o desempenho médio desse grupo é
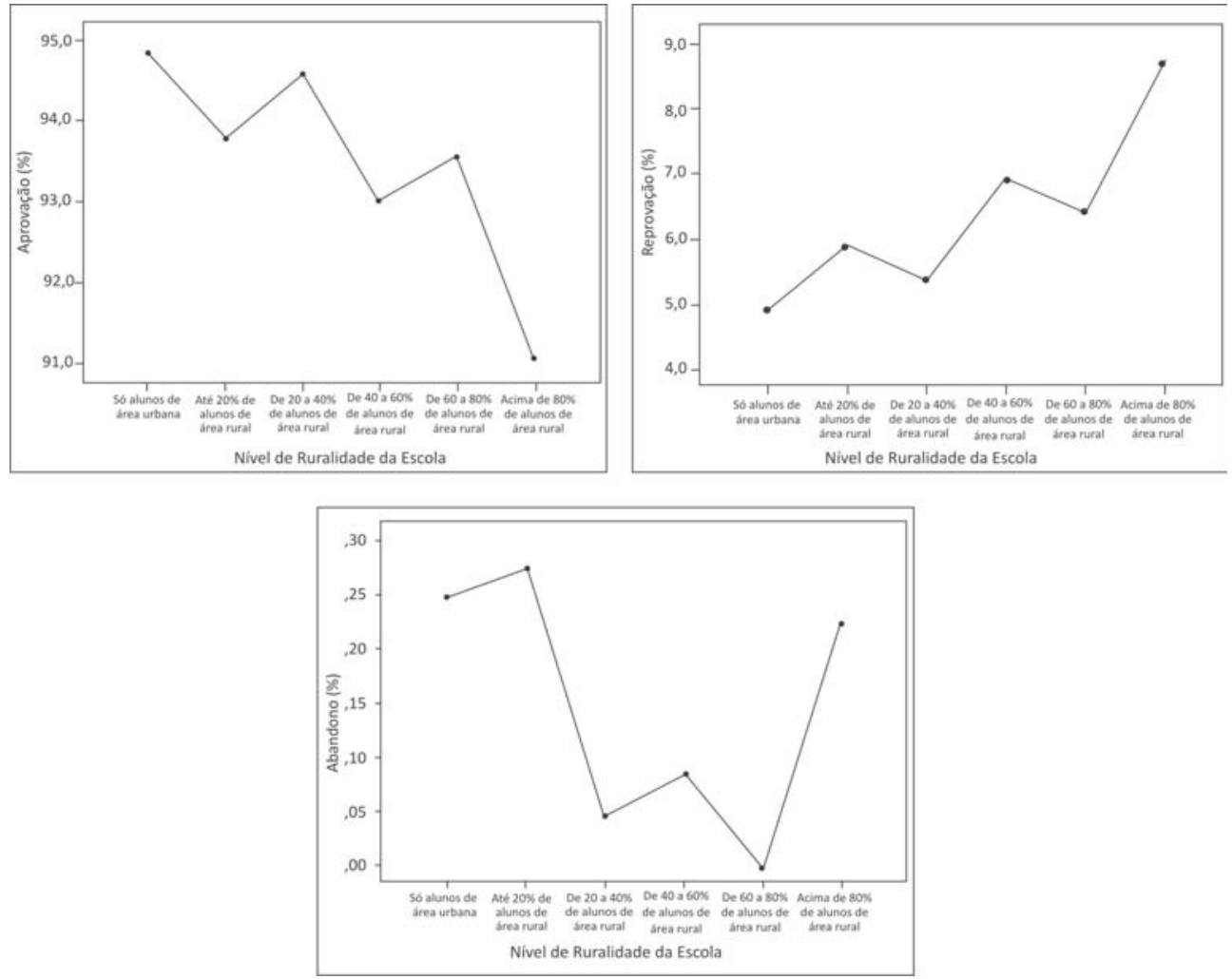

Fonte: Prova Brasil 2009, Censo Escolar 2009 e Ideb 2009.

Figura 3: Desempenho das escolas estaduais considerando o índice de ruralidade 
fortemente influenciado pelo Município de São Paulo e pelo Município de Osasco que, dentro desse grupo específico, estão entre as piores notas médias. De forma geral, os outros municípios que compõem esse grupo apresentam notas médias mais elevadas, salvo algumas exceções. Esses dados sugerem que, além da questão da ruralidade e das políticas públicas para a educação do campo, existem outros fatores, como renda, classe social e condições de vida em grandes centros urbanos, que podem influenciar o desempenho dos alunos e, consequentemente, das escolas, merecendo estudos e análises mais profundos.

Ao observar as escolas que possuem $40 \%$ ou mais dos alunos de área rural, percebe-se queda acentuada no desempenho quando comparadas com as escolas com baixa presença de alunos residentes na zona rural.

Os dados de aprovação, reprovação e abandono das escolas não estabelecem uma tendência de aumento ou queda de desempenho, sendo, portanto, muito difícil relacionar o nível de ruralidade das escolas e respectivos desempenhos.

Novamente, realizou-se o teste de Bonferroni para identificar entre quais grupos se deu a diferença. Assim, no caso das escolas da rede municipal, observouse que as escolas que só tinham alunos residentes em zonas urbanas apresentaram desempenho inferior, estatisticamente significante $(a ́=0,05)$ em todos os itens avaliados, quando comparadas a todos os outros grupos. A partir daí, as escolas com alto nível de ruralidade (acima de 60\%) apresentaram desempenho inferior, estatisticamente significante nas provas de matemática e língua portuguesa e também no Ideb, quando comparadas às escolas com baixo nível de ruralidade (até 40\%).

Como alternativa à avaliação da relação entre o índice de ruralidade das escolas e os indicadores de desempenho, procedeu-se ao cálculo dos coeficientes de correlação (Bravais-Pearson) entre o índice de ruralidade (varia de 0 a 1) e as variáveis investigadas neste estudo. Verifica-se que, dos seis coeficientes calculados, embora baixos, vários deles são significativos do ponto de vista estatístico. Na rede estadual, observou-se que a nota na prova de língua portuguesa, o Ideb, a aprovação e o abandono têm relação inversa com o índice de ruralidade, ou seja, quanto maior o nível de ruralidade, pior o desempenho nesses índices. Em relação à reprovação, a relação é positiva, o que também representa um pior desempenho à medida que o índice de ruralidade aumenta. Na rede municipal, as correlações significantes são entre o índice de ruralidade, a prova de língua portuguesa e o Ideb. Quanto maior o índice de ruralidade, pior o desempenho nesses dois itens, dado que a relação é negativa. Quando se analisa os dados agrupados, independente da rede de ensino, observa-se a relação 
estatisticamente significante entre o índice de ruralidade, a nota na prova de língua portuguesa, o Ideb e a reprovação.

Dessa forma, verifica-se que, de modo geral, tanto para as escolas estaduais quanto municipais, o desempenho das escolas é reduzido conforme aumenta o
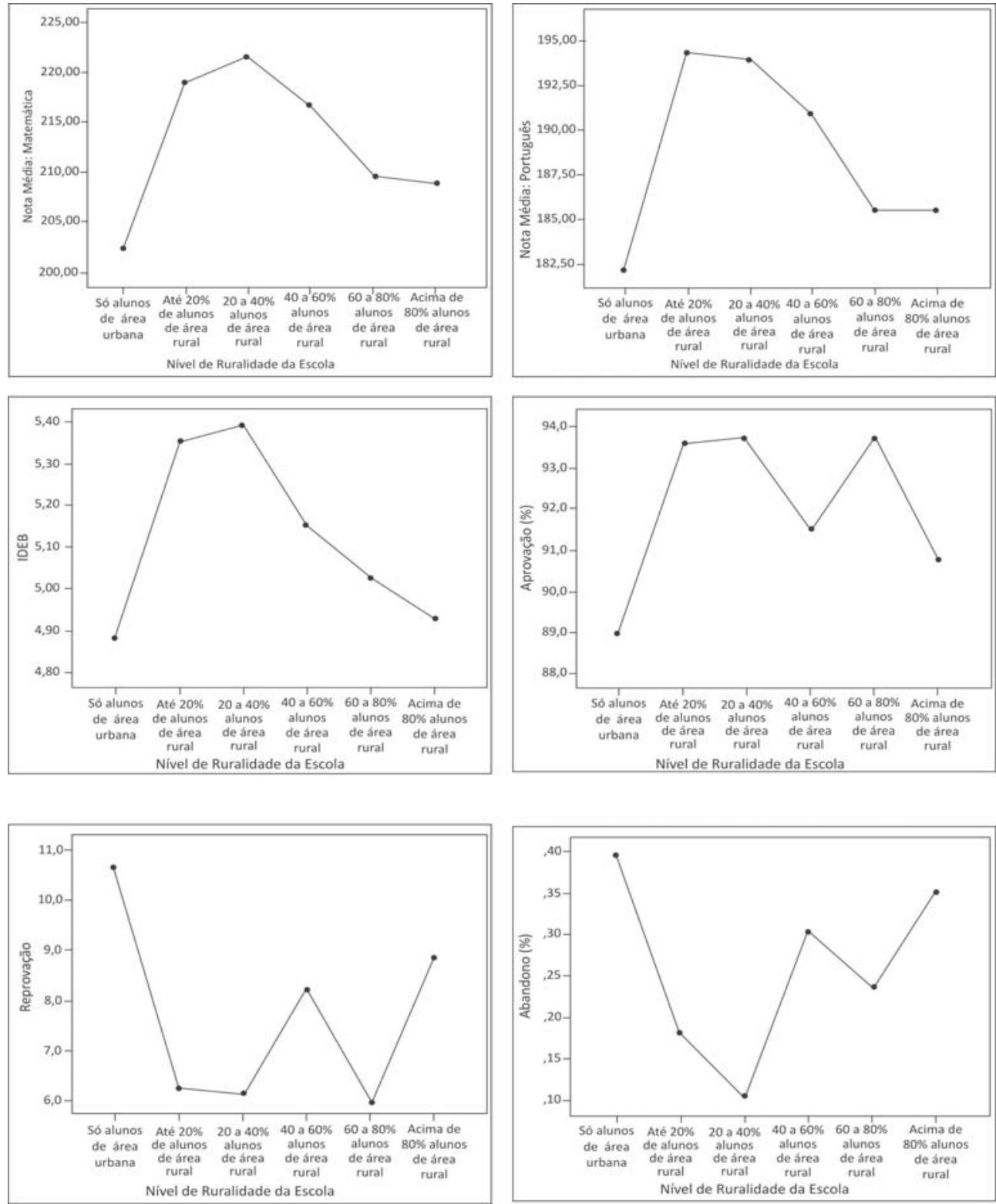

Fonte: Prova Brasil 2009, Censo Escolar 2009 e Ideb 2009.

Figura 4: Desempenho das escolas municipais considerando o índice de ruralidade 
Tabela 8: Correlação de Pearson entre o índice de ruralidade e os indicadores de desempenho

\begin{tabular}{|c|c|c|c|c|c|c|}
\hline & \multicolumn{2}{|c|}{ Estadual } & \multicolumn{2}{|c|}{ Municipal } & \multicolumn{2}{|c|}{ Geral } \\
\hline & Correlação & Sig. & Correlação & Sig & Correlação & Sig \\
\hline Matemática &,- 020 & ,374 & ,005 & ,762 & ,004 & ,740 \\
\hline Língua Portuguesa &,$- 065^{* *}$ &, 005 &,$- 034^{*}$ & 028 &,$- 035 * *$ & ,007 \\
\hline IDEB &,- 033 & , 148 &,$- 042^{* *}$ & ,007 &,$- 042^{* *}$ &, 001 \\
\hline Aprovação &,$- 051^{*}$ &, 024 & - ,007 & 641 &,- 023 & ,070 \\
\hline Reprovação & ,061** & ,008 & ,007 & ,646 &, $026^{*}$ & ,046 \\
\hline Abandono &, $067 * *$ & ,003 & ,002 & 892 &,- 020 & 120 \\
\hline
\end{tabular}

Fonte: Prova Brasil 2009, Censo Escolar 2009 e Ideb 2009.

percentual de alunos de área rural, demonstrando que, conforme discutido por Arroyo (2011), a mistura de alunos de realidades desiguais reflete nos desempenhos desiguais dentro das escolas. Cabe repensar, nesse ponto, a respeito da desigualdade refletida no contexto escolar ao aumentar o percentual de alunos de origem rural, junto com os alunos de origem urbana. $E$, sob essa ótica, embora nos últimos anos as iniciativas para a educação do campo tenham aumentado consideravelmente, há de se observar que, além da educação do campo e a educação da cidade, existe uma situação mista em que, na maior parte das iniciativas, são tratadas apenas como educação da cidade, sem considerar a origem e a moradia rural dos alunos.

\section{Considerações finais}

A educação do campo é um tema relativamente novo. As primeiras ações vieram nas últimas décadas, tal como a aprovação da Lei das Diretrizes Básicas da Educação Nacional, os constantes movimentos sociais, as conferências nacionais referentes à educação do campo, a criação da Secadi e projetos como o "Projovem Campo" e a "Educação Infantil no Campo". As políticas públicas de educação do campo vêm seguindo, de certa forma, o mesmo padrão de implementação: primeiramente, ocorre a publicação de uma legislação quanto a um referido tema de educação do campo que, não só dá base para a criação de ações, como torna o tema foco para novos estudos. Depois, ocorrem as discussões que são consequências da grande demanda existente. Cria-se um plano para 
atender às necessidades e, finalmente, ocorre a implementação da política pública.

Portanto, é perceptível uma evolução no tema que foi, primeiramente, adotado como lei, depois, como discussões no País em forma de conferências, que geraram a criação de uma secretaria e, por fim, a prática de projetos com o objetivo de sanar a deficiência da educação do campo, e de um Movimento Nacional pela Educação do Campo.

E, ainda, a luta dos povos do campo (ribeirinhos, lavradores, extrativistas, quilombolas, acampados, assentados etc.) pela transformação de suas condições de reprodução social diz respeito às origens coloniais da história brasileira. Raramente presente no discurso oficial, a história dessa luta permeia diversos momentos em que as disputas pelo território brasileiro colocaram em confronto a expansão do latifúndio e a reprodução do campesinato, explicitando a contradição entre projetos opostos de campo e de Nação. O movimento da educação do campo representa a continuidade histórica desse processo a partir da década de 1990, no período de emergência dos movimentos sociais rurais no contexto da sociedade civil organizada, depois de um gigante período de clandestinidade durante a Ditadura Militar no Brasil. Assim, a partir desse momento, tem início entre os povos do campo a construção de uma perspectiva crítica sobre a educação oficialmente dirigida para o meio rural, a chamada "educação rural", e a construção do que veio a ser denominado de educação do campo.

Entretanto, verifica-se que, tanto no Inep quanto no MEC, a educação ofertada para áreas rurais ainda está entrelaçada no que era a chamada educação rural, e evoluiu apenas na nomenclatura formal para o que passou a ser chamado de educação do campo. Isto é, a educação do campo, no Inep e no MEC, continua sendo aquela ofertada fora dos perímetros urbanos.

O movimento da educação do campo não é apenas um movimento político ou um movimento de renovação pedagógica, mas um movimento para a construção de uma epistemologia que dê base ao que passou a ser chamado de educação do campo, com novas perspectivas teóricas, inclusive dentro das universidades brasileiras. Nesse contexto, cada vez mais, é relevante o aparecimento dos observatórios de educação do campo, como o existente na Universidade de Brasília (unindo oito universidades brasileiras) ou no Instituto de Educação do Campo e Desenvolvimento Territorial Sustentável da Universidade Federal de Santa Catarina, unindo ensino, pesquisa e extensão (MolınA; Mourão Sá, 2011).

Verifica-se, nas universidades brasileiras, um substrato de produção de conhecimento na perspectiva do movimento social por políticas públicas de educação do campo no Brasil, que considere as ruralidades e as identidades do 
campo. Uma política pública diferenciada para a educação do campo tem que considerar justamente o que é campo.

Como forma de avaliar o desempenho da educação do campo e a efetividade das políticas públicas destinadas a essa área, buscou-se analisar o desempenho do Estado de São Paulo. Certamente, a limitação do estudo a esse estado traz consequências, pois, ao ser considerado o estado mais urbano do País, poucos são os estudos sobre ambiente rural e educação rural que são conduzidos nessa região. Destaca-se que, no Brasil, a preocupação com o cenário rural possui um grande foco nas regiões consideradas mais pobres do ponto de vista econômico, como as regiões Norte e Nordeste.

Os dados da Prova Brasil 2009, o Ideb 2009 e as taxas de aprovação, reprovação e abandono escolar do mesmo ano foram analisados comparando os resultados das escolas das áreas urbana e rural, de acordo com dois critérios de ruralidade: a classificação do IBGE e o perfil dos alunos das escolas que considera a proporção de alunos residentes em áreas rurais em relação ao total de alunos da escola.

Identificou-se que ao considerar a tipologia do IBGE, a educação na área rural (educação do campo) apresenta resultados que demonstram sua fragilidade; entretanto, o limite de 20 alunos matriculados na série avaliada reduz o poder de análise do desempenho das escolas de menor porte. A amostra de escolas que participaram da Prova Brasil consiste, em grande parte, de escolas com maior quantidade de alunos, que não refletem a realidade das escolas do campo do estado, compostas em sua maioria por escolas pequenas. Além disso, verificou-se um percentual muito baixo de escolas rurais que participaram da avaliação, embora esse tenha sido o primeiro ano que essas escolas participaram dessa prova.

Por outro lado, as categorias e os indicadores construídos neste trabalho buscaram explorar ao máximo as informações contidas nas bases de dados do Inep. No entanto, talvez não sejam, necessariamente, os melhores do ponto de vista conceitual, pelo fato da necessidade de adaptação aos dados já disponíveis na base de dados. Esse fato constituiu-se em um dos limites desta pesquisa, sem comprometer os resultados da mesma, pois se acreditou que tais categorias e seus indicadores se mostraram relevantes.

A análise que trata do nível de ruralidade das escolas apresenta resultados nos quais se verifica que a mistura entre alunos de área rural e urbana leva a uma queda no desempenho escolar. Essa queda de desempenho pode ser compreendida a partir da discussão de Arroyo (2011), na qual o autor pontua que as escolas com maior desigualdade no desempenho são escolas cujos alunos também são provenientes de coletivos desiguais. Sendo assim, "os desiguais em 
qualidade social, racial e cultural são destacados como os responsáveis pela desigual qualidade das escolas" (Arroyo, 2011, p. 86).

Assim, as políticas públicas e as iniciativas direcionadas à educação do campo deveriam considerar também essa situação mista, em que os alunos de procedência rural se submetem aos mesmos mecanismos dos alunos urbanos, não sendo consideradas as especificidades daqueles.

\section{Referências bibliográficas}

Alves, T.; Passador, C. S. Educação pública no Brasil: condições de oferta, nível socioeconômico dos alunos e avaliação. São Paulo: Annablume; Brasília, DF: Capes/ Inep, 2011.

Arroyo, M. G. Políticas de formação de educadores (as) de campo. Cadernos Cedes, Campinas, v. 27, n. 72, p. 157-176, 2007.

BAPTISTA, F. M. C. Educação rural: das experiências à política pública. 2. ed. Brasília, DF: Conselho Nacional de Desenvolvimento Rural Sustentável/Ministério do Desenvolvimento Agrário/Editorial Abaré, 2003.

Brasil. Constituição da República dos Estados Unidos do Brasil de 1934. Rio de Janeiro: Imprensa Nacional, 1934.

. Constituição da República Federativa do Brasil de 1988. Rio de Janeiro: Imprensa Nacional, 1988.

. Decreto-lei no 9.613, de 20 de agosto de 1946. Lei Orgânica do Ensino Agrícola. Estabelece as bases de organização e de regime do ensino agrícola, que é o ramo do ensino até o segundo grau, destinado essencialmente à preparação profissional dos trabalhadores da agricultura. [S.I.: S. n.], 1946.

. Lei no 4.024, de 20 de dezembro de 1961. Fixa as diretrizes e bases da educação nacional. Diário Oficial da União, Brasília, DF, 27 dez. 1961. Seção 1, p. 11429, 1961.

. Lei no 9.394, de 20 de dezembro de 1996. Lei de Diretrizes e Bases da Educação Nacional. Estabelece as diretrizes e bases da educação nacional. Diário Oficial da União, Brasília, DF, 23 dez. 1996. Seção 1, p. 27833, 1996.

Ministério da Educação. Plano Nacional de Desenvolvimento do Ensino Agrícola de 2o Grau, 1973.

. Ministério da Educação. Procampo. 2011a. Disponível em: <http:// portal.mec.gov.br/index.php?option=com_content\&view=article\&id= 12395\&Itemid=677>. Acesso em: jun. 2011.

. Ministério da Educação. Secretaria de Educação Continuada, Alfabetização, Diversidade e Inclusão (SECADI). Programas e ações. 2009b. 
Disponível em: <http://portal.mec.gov.br/index.php?option=com_content\&view= article\&id=290\& Itemid=816> . Acesso em: abr. 2011.

Ministério da Educação. Secretaria de Educação Continuada, Alfabetização, Diversidade e Inclusão. 2011b. Disponível em: <http:// portal.mec.gov.br/index.php?option=com_content\&view=article\&id=290\& Itemid=816>. Acesso em: jun. 2011.

Calazans, M. J. C.; Castro, L. F. M.; Silva, H. R. S. Questões e contradições da educação rural no Brasil. In: Werthein, J.; BordenAVE, J. D. (Orgs.). Educação rural no terceiro mundo. 2. ed. São Paulo: Paz e Terra, 1981.

CANÁRIO, R. A escola no mundo rural: contributos para a construção de um objecto de estudo. Educação, Sociedade \& Culturas, Lisboa, n. 14, p. 121-139, 2000.

Coutinho, A. F.; \& Teixeira, M. F. Educação do campo: processos e desafios de uma construção histórica. Ciências Humanas em Revista, São Luís, v. 7, n. 2, p. 1-12, 2009.

Damasceno, M. N.; \& Beserra, B. Estudos sobre educação rural no Brasil: estado da arte e perspectivas. Educação e Pesquisa, São Paulo, v. 30, n. 1, p. 73-89, 2004.

FEITosA, A. E. F. As mudanças estruturais do capitalismo rural e suas implicações na formação de técnicos em agropecuária: a extinção da Coagri/MEC. Trabalho Necessário, v. 5, n. 5, p. 1-15, 2007.

GIL, Antonio C. Métodos e técnicas de pesquisa social. 6. Ed. São Paulo: Atlas, 2002. GRITTI, S. M. Técnico em agropecuária: servir à agricultura familiar ou ser desempregado da agricultura capitalista. 252 f. Tese (Doutorado em Educação) - Faculdade de Educação, Universidade Federal do Rio Grande do Sul, Brasil, Porto Alegre, 2007.

HalR, Joseph F. et al. Análise multivariada de dados. Porto Alegre: Bookman, 2006. Instituto Brasileiro de Geografia Estatística (IBGE). Pesquisa Nacional por Amostra de Domicílios 2009 (PNAD). Disponível em: <http://www.ibge.gov.br/home/ estatistica/populacao/trabalhoerendimento/pnad2009/pnad_sintese_2009.pdf>. Acesso em: 12 abr 2011.

KLIKSBERG, B. Repensando o Estado para o desenvolvimento social: superando dogmas e convencionalismos. São Paulo: Cortez, 1998. Tradução Joaquim Ozório Pires da Silva. LEITE, S. C. Escola rural: urbanização e políticas públicas educacionais. São Paulo: Cortez, 2002.

MARTINS, P. S. O financiamento da educação básica como política pública. Revista Brasileira de Política e administração da educação, Porto Alegre, v. 26, n. 3, p. 497514, 2010.

MolınA, M. C. Desafios e perspectivas na formação de educadores: reflexões a partir da Licenciatura em Educação do Campo da Universidade de Brasília. (p. 369-388) In: DALBEN, A. et al. (Orgs.). Didática e prática de ensino. Belo Horizonte: Autêntica, 2010. 
Molina, M. C.; Montenegro, J. L. A.; Oliveira, L. L. N. A. Das desigualdades aos direitos: a exigência de políticas afirmativas para a promoção da equidade educacional no campo. Raízes - Revista de Ciências Sociais e Econômicas, Campina Grande, v. 28-29, n. 1-2, p. 174-190, 2010.

Molina, M. C.; \& Mourão SÁ, L. (Orgs.). Licenciatura em Educação do Campo. Belo Horizonte: Autêntica, 2011.

MunARIM, A. Movimento Nacional de Educação do Campo: uma trajetória em construção. In: Reunião Anual da Associação Nacional de Pós-Graduação e Pesquisa em Educação, 31.,Caxambu. Anais, 2008a . Disponível em: <http://www.anped.org.br/reunioes/31ra/ 1trabalho/GT03-4244-Int.pdf>. Acesso em: 22 abr. 2011.

. Trajetória do movimento nacional de educação do campo no Brasil. Educação, v. 33, p. 59-76, Santa Maria, 2008b.

Oliveira, M. R. D. Dos programas oficiais para a educação rural aos projetos de educação do campo dos movimentos sociais. Revista Labor, v. 1, n. 1, 2008.

PARAnÁ. Governo do Estado. Secretaria de Estado da Educação (SEED). Educação do campo. Curitiba: SEED, 2009.

PASSADOR, C. S. A educação rural no Brasil: o caso da escola do campo no Paraná. São Paulo: Annablume, 2006.

Richardson, R. J. Pesquisa social: métodos e técnicas. São Paulo: Atlas, 1999.

SILVA, M. S. Educação do campo e desenvolvimento: uma relação construída ao longo da história, 2004. Disponível em: <http://www.contag.org.br/imagens/f299Educacao_ do_Campo_e_Desenvolvimento_Sustentavel.pdf>. Acesso em: 16 fev. 2011.

VEIGA, J. E. Cidades imaginárias: o Brasil é menos urbano do que se calcula. Campinas: Ed. Autores Associados, 2002.

\footnotetext{
Cláudia Souza Passador

É doutora em Educação pela Universidade de São Paulo e professora associada do Departamento de Administração da Faculdade de Economia, Administração e Contabilidade de Ribeirão Preto da Universidade de São Paulo. Contato: cspassador@usp.br

José Eduardo Ferreira Lopes

É doutorando em Administração na Universidade de São Paulo e professor assistente da Faculdade de Gestão e Negócios da Universidade Federal de Uberlândia. Contato: jeflopes@fagen.ufu.br
} 
